THE

\title{
JOURNAL
}

OF

\section{SYMBOLIC LOGIC}

EDITED BY

WILFRIED BUCHHOLZ

HERBERT B. ENDERTON

MATTHEW FOREMAN

NEIL IMMERMAN
GERHARD JÄGER

RICHARD KAYE

STEFFEN LEMPP

PENELOPE MADDY

DAVID MARKER
WILLIAM MITCHELL

PHILIP SCOWCROFT

LOU VAN DEN DRIES

AlBert VISSER

\section{VOLUME 61}

1996

Published quarterly by the Association for Symbolic Logic, Inc. with SUPPORT FROM ICSU AND FROM INSTITUTIONAL AND CORPORATE MEMBERS 
The four numbers of Volume 61 were issued at the following dates:

\author{
Number 1, pages 1-352, March 25, 1996 \\ Number 2, pages 353-704, June 5, 1996 \\ Number 3, pages 705-1056, September 27, 1995 \\ Number 4, pages 1057-1400, December 2, 1996
}

Numbers 1-4 of this volume are copyrighted (c) 1996 by the Association for Symbolic Logic, Inc. Reproduction of copyrighted numbers of the JouRNAL by photostat, photoprint, microfilm, or like process is forbidden, except by written permission, to be obtained from the Secretary of the Association, C. Ward Henson, Department of Mathematics, University of Illinois, 1409 W. Green St., Urbana, IL 61801.

The paper used in this JoURNAL is acid-free and falls within the guidelines established to ensure permanence and durability. This JouRNaL has been registered with the Copyright Clearance Center, Inc. The appearance of a code at the bottom of the first page of an article indicates the copyright owner's consent for copying beyond that permitted by Sections 107 or 108 of the U. S. Copyright Law, provided that the per-copy fee stated in the code is paid directly to Copyright Clearance Center, Inc., 222 Rosewood Drive, Danvers, MA 01923. This consent does not extend to copying for general distribution, for advertising or promotion purposes, for creating new collective works, or for resale. Specific written permission for such copying must be obtained from the Association. 


\section{CONTENTS OF VOLUME 60}

\section{RESEARCH PAPERS}

Alechina, Natasha and van Lambalgen, Michiel. Generalized quantification as substructural logic ......................... 1006

Ambos-Spies, Klaus, Fejer, Peter A., Lempp, Steffen, and Lerman, MANUEL. Decidability of the two-quantifier theory of the recursively enumerable weak truth-table degrees and other distributive upper semilattices

APTER, ARTHUR W. AD and patterns of singular cardinals below $\Theta \ldots \ldots \quad 225$

AVIGAD, JerEMY. On the relationship between $A T R_{0}$ and $\widehat{I D}_{<\omega} \ldots \ldots \ldots . \ldots 768$

Bartoszyński, TomeK, RosŁanowski, Andrzej, and Shelah, Saharon. Adding one random real.............................. 80

BeKLEMISHEv, Lev D. Bimodal logics for extensions of arithmetical theories 91 Berarducci, Alessandro and Otero, Margarita. A recursive nonstandard model of normal open induction...................... 1228

BRaDY, Ross T. Gentzenizations of relevant logics without distribution. I. 353 . Gentzenizations of relevant logics without distribution. II...... 379 . Gentzenizations of relevant logics with distribution ........... 402 Simple Gentzenizations for the normal formulae of contraction-

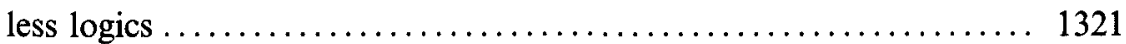

Calmoun, William C. and Slaman, Theodore $\mathrm{A}$. The $\Pi_{2}^{0}$ enumeration de-

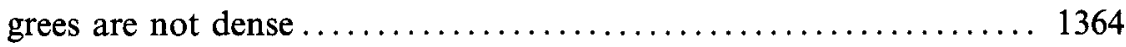

Casanovas, EnRique and Farré, Rafel. Omitting types in incomplete theories ............................................

Cegielski, Patrick, Matiyasevich, Yuri, and Richard, Denis. Definability and decidability issues in extensions of the integers with the divisibility predicate

Chowdhury, Ambar, Loveys, James, and Tanović, Predrag. A definable continuous rank for nonmultidimensional superstable theories.......

Cifuentes, J. D., Sette, A. M., and Mundici, D. Cauchy completeness in

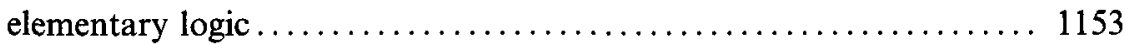

CoOPer, S. BARRY and Sorbi, ANDrea. Noncappable enumeration degrees below $\mathbf{0}_{e}^{\prime}$

DASGUPTA, ABHIJIT. Boolean operations, Borel sets, and Hausdorff's question

Dellunde, Pilar and Jansana, Ramon. Some characterization theorems for infinitary universal Horn logic without equality 
Delon, Françoise and Farré, Rafel. Some model theory for almost real

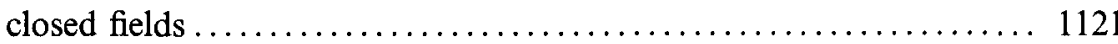

Dow, Alan. On Boolean subalgebras of $\mathscr{P}\left(\omega_{1}\right) /$ ctble $\ldots \ldots \ldots \ldots \ldots \ldots . \quad 873$

ENSLEY, Douglas E. Automorphism-invariant measures on $\aleph_{0}$-categorical structures without the independence property ............... 640

Farré, Rafel. See Casanovas, ENRIQue

See Delon, Françoise

Fejer, Peter A. See Ambos-Spies, Klaus

Finkel, O. and Ressayre, J. P. Stretchings .................... 563

GabBay, D. M. Fibred semantics and the weaving of logics. Part 1: Modal

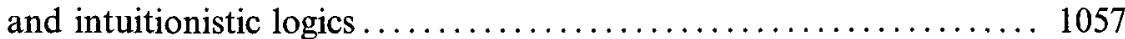

Ghilardi, Silvio and Meloni, Giancarlo. Relational and partial variable sets and basic predicate logic ........................ 843

GILCHRIST, M. and SHELAH, S. Identities on cardinals less than $\aleph_{\omega} \ldots \ldots \ldots 780$

GLass, Thomas. On power set in explicit mathematics .............. 468

Groszex, Marcia J., Mytilinaios, Michael E., and Slaman, Theodore A. The Sacks density theorem and $\Sigma_{2}$-bounding $\ldots \ldots \ldots \ldots \ldots \ldots \ldots 450$

Grove, Adam J., Halpern, Joseph Y., and Koller, Daphne. Asymptotic conditional probabilities: The non-unary case .............. 250

Gurevich, Yuri and Shelah, Saharon. On finite rigid structures ....... 549

HALBEISEN, LoRENZ and JUdAH, HaIm. Mathias absoluteness and the Ramsey property

Hapern, Joseph Y. See Grove, Adam J.

Hella, LaURI, LuOSTO, KerkKo, and VÄÄNÄNEN, Jouko. The hierarchy theorem for generalized quantifiers....................... 802

Hirokawa, SaChio. The proofs of $\alpha \rightarrow \alpha$ in $P-W \ldots \ldots \ldots \ldots \ldots . \ldots . . \ldots 195$

HJorth, GreG. On $\aleph_{1}$ many minimal models.................... 906

Variations of the Martin-Solovay tree .................... 40

HORSTEN, LEON. Reflecting in epistemic arithmetic................. 788

Iovino, José. The Morley rank of a Banach space................. 928

JÄGER, Gerhard and STRAhM, Thomas. Some theories with positive induction of ordinal strength $\varphi \omega 0 \ldots \ldots \ldots \ldots \ldots \ldots \ldots \ldots \ldots \ldots \ldots \ldots$

Jansana, Ramon. See Dellunde, Pilar

Jech, Thomas and Shelah, Saharon. On countably closed complete Boolean algebras ................................... 1380

Possible PCF algebras ............................. 313

Judah, Haim. See Halbeisen, LoRenz 
Kanover, Vladimir. On external Scott algebras in nonstandard models of

Peano arithmetic.

KHELIF, ANATOLE. Existentially closed models via constructible sets: There are $2^{\aleph_{0}}$ existentially closed pairwise non elementarily equivalent existentially closed ordered groups........................

Koller, Daphne. See Grove, Adam J.

Kotlarski, Henryk. An addition to Rosser's theorem...............

Kumabe, Masahiro. Minimal complementation below uniform upper bounds for the arithmetical degrees $\ldots \ldots \ldots \ldots \ldots \ldots \ldots \ldots \ldots \ldots \ldots$

Laflamme, Claude. A few special ordinal ultrafilters.............. 920

LAFONT, YVES. The undecidability of second order linear logic without ex-

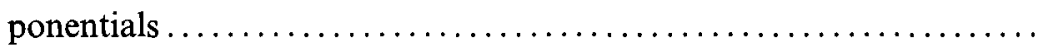

Laskowski, Michael C. and MaYer, LaUra L. Stable structures with few

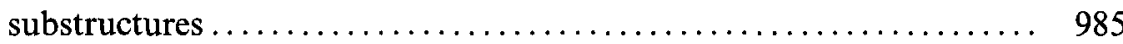
and SHELAH, S. Forcing isomorphism II................ 1305

Lempr, Steffan. See Ambos-Spies, Klaus

Lerman, Manuel. See Ambos-Spies, Klaus

LifsChes, ShMuel and Shelah, Saharon. Uniformization, choice functions and well orders in the class of trees ..................... 1206

Loveys, James and Tanović, Predrag. Countable models of trivial theories

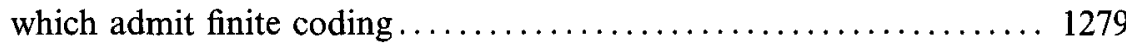

See Chowdhury, Ambar

Luosto, Kerkko. See Hella, Lauri

Maddy, PENELope. Set theoretic naturalism

Matiyasevich, Yuri. See Ceggielski, Patrick

Mayer, Laura L. See Laskowski, Michael C.

Meloni, Giancarlo. See Ghilardi, Silvio

Mints, Grigori. Strong termination for the epsilon substitution method. . 1193

Mundici, D. See Cifuentes, J. D.

Mytilinaios, Michael E. See Groszek, Marcia J.

NEWELSKI, LUDOMIR. On atomic or saturated sets .............. 318

Otero, Margarita. See Berarducci, Alessandro

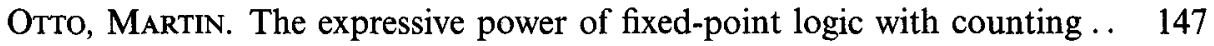

Purdy, William C. Fluted formulas and the limits of decidability ....... 608

RATHJEN, Michael. Monotone inductive definitions in explicit mathematics 125

Ressayre, J. P. See Finkel, O.

Richard, Denis. See Cegielski, Patrick

RosŁanowski, ANDrzej. See Bartoszyński, TomeK 
SCHEEPERS, MARION. Lebesgue measure zero subsets of the real line and an infinite game

SChimmerling, E. and SteEL, J. R. Fine structure for tame inner models . 621 Sette, A. M. See Cifuentes, J. D.

ShelaH, SAHARon. If there is an exactly $\lambda$-free abelian group then there is an exactly $\lambda$-separable one in $\lambda$

\section{See BARTOSZYŃSKI, TOMEK}

. See GILCHRIST, M. See GurEVICH, YuRI

. See JeCh, Thomas

See Laskowski, Michael C.

See Lifsches, SHMuEL

SHER, G. Y. Did Tarski commit "Tarski's fallacy"?

Slaman, Theodore A. See Calhoun, William C. See GroszeK, Marcia J.

Sorbi, ANDrea. See CoOper, S. BARrY

Steel, J. R. See Schimmerling, E.

Strahm, Thomas. See Jäger, Gerhard

Tanović, Predrag. See Chowdhury, Ambar See Loveys, James

TAYLOR, PAUL. Intuitionistic sets and ordinals

VäÄnÄnEn, Jouko. See Hella, Lauri

van Lambalgen, Michiel. See Alechina, Natasha

VAN OOSTEN, JAAP. Two remarks on the Lifschitz realizability topos ......

Veldman, Wim and WaAldijk, Frank. Some elementary results in intuitionistic model theory.

WaAldijk, Frank. See Veldman, Wim

WEIERMANN, ANDREAS. How to characterize provably total functions by local predicativity

WELCH, P. D.. Countable unions of simple sets in the core model....... 293

WESTERSTÅHL, DAG. Self-commuting quantifiers ................ 212

ZaKharyaschev, Michael. Canonical formulas for K4. Part II: Cofinal subframe logics................................... 421

ZAMBELlA, DOMENICO. Notes on polynomially bounded arithmetic.

ZANARDO, AlBERTo. Branching-time logic with quantification over branches: The point of view of modal logic

\section{REVIEWS}

Reviews 


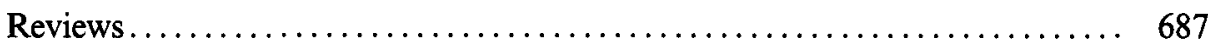

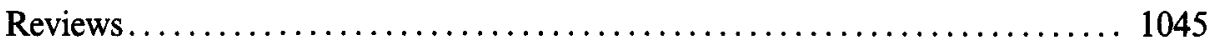

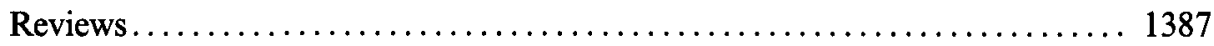




\section{ERRATA}

VOLUME 61

Page 68, line 8. In the statement of Theorem 3 of How to characterize provably total functions by local predicativity, by Andreas Weiermann, replace 《where $F(x, y)$ is a $\Delta_{0}$-formula》 by 《where $F(x, y)$ is a $\Sigma(\omega)$-formula $)$. The proof of Theorem 3 does go through without essential changes for this more general formulation (which in fact is necessary for describing recursive functions in the language of $K P(\omega)$. More details can be found, for example, in B. Blankertz and A. Weiermann, $A$ uniform approach for characterizing the provably total number-theoretic functions of $K P M$ and (some of) its subsystems, Proceedings of Logic Colloquium '94, Studia logica (to appear).

Page 69, line 20. For $\langle\langle 115-147\rangle$, read $\langle\langle 27-78\rangle$.

Page 276. In the references to the paper Asymptotic conditional probabilities: the non-unary case, by Adam Grove, Joseph Halpern and Daphne Koller, item 25 should be replaced by the following: «[25] J. LYNCH, Probabilities of first-order sentences about unary functions, Transactions of the American Mathematical Society, vol. 287 (1985), pp. 543-568.»)

Page 341, last line. For 《 1990》, read 《(1991》.

Page 399. The displayed formula at the bottom of the page should be moved up two lines, between «Thus, 》 and « where».

Page 1052, line 17 from below. For 《 Aufgabe 8.1.5》, read 《Aufgabe 1.8.5»). 
Institutional membership in the Association is available to any academic institution or department. Annual institutional dues are $\$ 425$ for 1996 . Membership privileges include choices of current subscriptions, of back volumes, and of student memberships. A detailed description of institutional and corporate membership is available from the Secretary-Treasurer of the Association.

Information on microfiche and microfilm editions of the JOURNAL may be obtained from University Microfilms, 300 North Zeeb Road, Ann Arbor, MI 48106, U.S.A.

Back volumes of the Journal are available. Prices per volume in paper form are as follows: $\$ 65$ for Volumes 1-13; \$130 for Volumes 14-30; \$150 for Volumes 31-45; \$195 for Volumes 46-47; \$255 for Volumes 48-49; \$225 for Volumes 50-52; \$255 for Volumes 53-54, and \$290 for Volume 55-60. Volume 26 is an index for Volumes 1-26 and Number 4 of Volume 45 is an index for Volumes 27-45. Number 4 of Volume 55 is a cummulative index for Volume 27 through Volume 55 (it includes the index published in Volume 45, Number 4, except for listings of reviews by subject, which has been discontinued). The indexes through Volume 45 may be purchased together for $\$ 170$, and the cumulative index for Volumes $27-55$ may be purchased as a single issue for $\$ 70$. Members of the Association may purchase back volumes for their personal use at a $50 \%$ discount. A revised edition of $\boldsymbol{A}$ Bibliography of Symbolic Logic by Alonzo Church may be purchased separately; the price is $\$ 17$ for members and \$34 for nonmembers.

Requests for information, applications for membership, orders for back volumes, business correspondence, and notices and announcements for publication in the JourNaL should be sent to the Secretary-Treasurer of the Association, C. Ward Henson, ASL, Department of Mathematics, University of Illinois, 1409 W. Green Street, Urbana, IL 61801, U.S.A. The Internet address of the Association's business office is asl@math.uiuc.edu.

Notices of change of address, dues, and subscriptions to the Journal should be sent to the Association for Symbolic Logic, Journals Division UIP, 1325 South Oak Street, Champaign, IL 61820, U.S.A. All orders must be accompanied by payment in dollars; Visa and Mastercard are accepted. To receive a replacement copy of the JouRNAL, please report damaged, defective, or missing issues within nine months of the date of publication.

Books for review in the Journal should be sent to Herbert Enderton, The Journal of Symbolic Logic, U.C.L.A., Los Angeles, CA 90095, U.S.A. The other editors of reviews are Matthew Foreman, Gerhard Jäger, Penelope Maddy, and Philip Scowcroft.

Articles being submitted for publication in the JouRnal should be sent in duplicate to one of the following editors: Wilfried Buchholz, Mathematisches Institut, Universität München, Theresienstrasse 39, D-80333 München, Germany; or Sy D. Friedman, Department of Mathematics, Massachusetts Institute of Technology, Cambridge, MA 02139, U.S.A.; or Richard Kaye, School of Mathematics and Statistics, University of Birmingham, Edgbaston, Birmingham B15 2TT, England; or Steffen Lempp, School of Mathematics University of Leeds, Leeds LS2 9JT, England; or David Marker, Department of Mathematics, m/c 249, University of Illinois at Chicago, 851 S. Morgan Street, Chicago, IL 60607, U.S.A.; or William J. Mitchell, Department of Mathematics, University of Florida, Gainesville, FL 32611, U.S.A.; or Lou van den Dries, Department of Mathematics, University of Illinois, 1409 W. Green Street, Urbana, IL 61801, U.S.A.; or Albert Visser, Department of Philosophy, Utrecht University, Heidelberglaan 8, P. O. Box 80126, 3508 TC Utrecht, The Netherlands.

Each manuscript should be typewritten with wide margins and with double spacing between the lines. Footnotes should be numbered consecutively and should also be typed with wide margins and double spacing, preferably on a separate sheet. Two copies of the manuscript should be sent to the editor, and the author should also keep a complete copy. After the paper is accepted in its final form, an electronic copy in $\mathrm{LT}_{\mathrm{E}} \mathrm{X}, \mathcal{A}_{\mathcal{M}} \mathcal{S}$-LATEX, or $\mathcal{A}_{\mathcal{M}} \mathcal{S}$-T $\mathrm{T}$ X $\mathrm{T}$ format would be useful. Fifty offprints of each article are supplied at no charge, and additional offprints may be purchased if desired.

The Journal invites submission of (1) original technical papers in the field of symbolic logic, (2) expository papers in this field, (3) papers whose main point is philosophical and which either bear upon logic or make use of its methods, and (4) studies in the history of logic in which modern technical developments are taken into account.

The paper used in this JOURNAL is acid-free and falls within the guidelines established to ensure permanence and durability. 


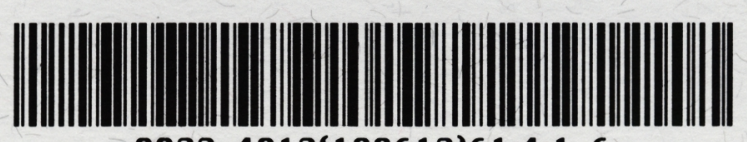

$0022-4812(199612) 61: 4 ; 1-6$ 